\title{
Prevalence of Chlamydia trachomatis and Neisseria gonorrhoeae infections among pregnant women and eye colonization of their neonates at birth time, Shiraz, Southern Iran
}

\author{
Bahman Pourabbas ${ }^{1}$, Zahra Rezaei ${ }^{1}$, Jalal Mardaneh ${ }^{2}$, Mozhgan Shahian ${ }^{1}$ and Abdolvahab Alborzi ${ }^{*}$
}

\begin{abstract}
Background: Chlamydia trachomatis and Neisseria gonorrhoeae are the two common transmissible pathogens from pregnant women to their neonates. Given the lack of routine screening and treatment of pregnant women in some areas, the possibility of transmission rises. This study seeks to determine the prevalence of $C$. trachomatis and $\mathrm{N}$. gonorrhoeae in the pregnant women with no clinical symptoms and the vertical transmission rate to their neonates.

Methods: The study was conducted on endocervical and eye swab samples of 239 pregnant women and their neonates. Identification was based on PCR method.

Results: The prevalence rates of C.trachomatis in women and neonates were 37/239 (15.5\%) and 28/239 (11.7\%), and for N. gonorrhoeae $3 / 239(1.3 \%), 1 / 239(0.4 \%)$, respectively. The vertical transmission rates to the neonates were $28 / 37(75.6 \%)$ for C. trachomatis and 1/3 for $N$. gonorrhoeae.

Conclusions: In the areas with a high prevalence of chlamydial or gonococcal infections, and in the absence of screening and treatment of the pregnant women, ocular prophylaxis with antibiotics is suggested as a part of routine neonatal care program for the prevention of chlamydial and gonococcal ophthalmia.
\end{abstract}

Keywords: C. Trachomatis, N. Gonorrhoeae, Pregnant women, Vertical transmission, Eye colonization

\section{Background}

C. trachomatis and N. gonorrhoeae are the common prevalent sexually transmitted bacteria capable of infecting men, women and neonates worldwide, especially in developing nations $[1,2]$. The estimated global prevalence in 2012 was 131 million cases of C. trachomatis and 78 million cases of $N$. gonorrhoeae in adults between the age of 15 and 49 years [2]. The annual estimation indicates different rates of infection in various parts of the world, ranging between $1.9-30.6 \%$ in pregnant women [2] and $1.6-18 \%$ in the neonates [3, 4] for C. trachomatis and for N. gonorrhoeae $0.08-7 \%$ [2] and $0.06-0.4 \%$ [3,

\footnotetext{
* Correspondence: Alborziiraj2004@yahoo.com

${ }^{1}$ Professor Alborzi Clinical Microbiology Research Center, Shiraz University of Medical Sciences, Shiraz, Iran

Full list of author information is available at the end of the article
}

5], respectively. In Iran, the results of a meta-analysis showed that the pooled prevalence rates of C. trachomatis in males and females were $10.9 \%$ (95\% CI, range: $7.6-$ $15.4 \%)$ and $12.3 \%$ (95\% CI, range: $10.6-14.2 \%)$, respectively [6]. Also, studies reported that prevalence of C. trachomatis in pregnant women was $2.2 \%$ to $14.79 \%$ [7-9]. As for $N$. gonorrhoeae, studies in Iran showed that its prevalence is 0 to $2.4 \%$ in people at low risk without symptoms [10]. One study on pregnant women revealed that $1.18 \%$ samples were positive for $N$. gonorrhoeae by PCR [11]. Infection with these organisms can cause a range of serious problems in mothers and newborns and can be asymptomatic in a significant proportion of the affected individuals $[12,13]$. C. trachomatis is the most frequent infectious agent accounting for $18 \%$ to $50 \%$ of all neonatal conjunctivitis and $3 \%$ to $20 \%$ of infantile

(c) The Author(s). 2018 Open Access This article is distributed under the terms of the Creative Commons Attribution 4.0 International License (http://creativecommons.org/licenses/by/4.0/), which permits unrestricted use, distribution, and reproduction in any medium, provided you give appropriate credit to the original author(s) and the source, provide a link to the Creative Commons license, and indicate if changes were made. The Creative Commons Public Domain Dedication waiver (http://creativecommons.org/publicdomain/zero/1.0/) applies to the data made available in this article, unless otherwise stated. 
pneumonia [14, 15]. About half of the neonates born from infected mothers with $N$. gonorrhoeae will develop neonatal conjunctivitis [16]. Untreated gonococcal conjunctivitis may lead to corneal scarring and blindness, whereas the risk of severe ocular damage is low with chlamydial infection which can cause purulent mucous, edema on the eyelids, papillary conjunctivitis, and the formation of pseudomembranes [16]. The transmission of these two organisms is usually through direct contact of the neonates with infected vagina at the time of delivery during vaginal birth but rarely occurs during Caesarean section [17].

Prenatal screening and treatment of pregnant women are highly recommended, but in Iran, the routine prenatal and prophylactic care to prevent these diseases in newborns is lacking, unlike some other countries in the developing world. The aim of this study is to determine the prevalence of $C$. trachomatis and $N$. gonorrhoeae in pregnant women admitted to the hospitals before delivery and respective vertical transmission rates to the neonates, using PCR method.

\section{Methods}

A total of 239 pregnant women referred to Hafez and Zeinabiye hospitals for delivery were enrolled in the study during 3 months. Over $50 \%$ of all the deliveries in Shiraz are performed in these two hospitals, with more than $60 \%$ vaginal delivery. Pregnant women from different regions and of various socioeconomic statuses are admitted. This study includes the women with vaginal delivery with no history of antibiotics prepartum and their neonates had not received prophylactic ophthalmic antibiotics, either. Endocervical and eye swab samples were obtained from the mothers and their neonates, respectively. The former were taken by a sterile cotton swab from endocervix before delivery and the latter by the scraping of upper lid conjunctiva, using a sterile cotton swab immediately after delivery. Both swabs were placed in separate tubes containing $500 \mu \mathrm{l}$ of sucrose phosphate transport medium (8 $\mathrm{mM} \mathrm{KH}_{2} \mathrm{PO}_{4}, 12 \mathrm{mM}$ $\mathrm{K}_{2} \mathrm{HPO}_{4}$ and $0.2 \mathrm{mM}$ sucrose) supplemented with antibiotics (amphotricin B $2.5 \mu \mathrm{g} / \mathrm{ml}$, streptomycin $50 \mu \mathrm{g} / \mathrm{ml}$ and vancomycin $100 \mu \mathrm{g} / \mathrm{ml}$ ) and transported to Professor Alborzi Clinical Microbiology Research Center, the same day for DNA extraction. The sample tubes were vortexed, swabs removed, and then, $250 \mu$ l of the sample transferred to a $1.5 \mathrm{ml}$ tube containing $250 \mu \mathrm{l} 10 \mathrm{mM}$ Tris- $\mathrm{HCl}, \mathrm{pH} 8.0$ and $1 \mathrm{mM}$ EDTA (TE). Each sample supplemented with $4 \mu \mathrm{l}$ proteinase $\mathrm{K}(10 \mu \mathrm{g} / \mathrm{ml})$ and $250 \mu \mathrm{l}$ TNNT buffer $(0.5 \%$ Tween $20,0.5 \%$ Nonidet P-40, $10 \mathrm{mM} \mathrm{NaOH}, 10 \mathrm{mM}$ Tris,pH 7.2), was incubated at $56{ }^{\circ} \mathrm{C}$ overnight and then, DNA extraction was performed using phenol chloroform method and finally, DNA resolved in $50 \mu \mathrm{l}$ TE buffer and stored at $-20{ }^{\circ} \mathrm{C}$.
Detection of $N$. gonorrhoeae and C. trachomatis was through two single-plex conventional PCR kits (Sacace Biothecnologies co. Italy) with specific primers for cryptic plasmid and amino acyltransferase gene. Five $\mu \mathrm{l}$ of DNA was amplified in a epgradiant thermocycler (eppendorf, Germany) using the following protocol: an initial denaturation $\left(94^{\circ} \mathrm{C}, 5 \mathrm{~min}\right)$, followed by 42 cycles of denaturation $\left(94{ }^{\circ} \mathrm{C}, 1 \mathrm{~min}\right)$, annealing $\left(54{ }^{\circ} \mathrm{C}, 1 \mathrm{~min}\right)$ and extension $\left(72{ }^{\circ} \mathrm{C}, 1 \mathrm{~min}\right)$, and a single final extension of $1 \mathrm{~min}$ at $72{ }^{\circ} \mathrm{C}$ for both C. trachomatis and $N$. gonorrhoeae, according to the manufacturer's instructions. These kits allow detecting DNA in $100 \%$ of the tests with a sensitivity of not less than 1000 copies/ml and a specificity of $100 \%$.

The collected data were entered into SPSS, version 18. The statistical relationship between the demographic data and infection was assessed using the chi-square and t-test.

\section{Results \\ Subjects}

Of the 239 studied women with vaginal delivery (mean age 27.7 ; range: $18-45$ years), $31.7 \%$ were illiterate or had primary education, $65 \%$ with secondary education, and $3.3 \%$ with university degrees. In total, $98 \%$ of them were housewives. The median gestational age was 39 weeks with a range of 32 to 44 weeks. Of the 239 studied neonates, $55 \%$ were male and $45 \%$ were female.

\section{Diagnosis of C. trachomatis and $N$. gonorrhoeae infection in pregnant women}

From 239 endocervical swabs, DNAs of C. trachomatis and $N$. gonorrhoeae were detected in $37(15.4 \%)$ and 3 (1.3\%), respectively. No case of co-infection with $N$. gonorrhoeae and C. trachomatis was observed.

No significant association was found between C.trachomatis, $N$. gonorrhoeae prevalence and age and educational status in the pregnant women in this study $(P$-value $>0.05)$.

\section{Diagnosis of C. trachomatis and $\boldsymbol{N}$. gonorrhoeae infection in neonates}

Of the 239 samples from neonatal eyes, DNAs of C. trachomatis and $N$. gonorrhoeae were detected in 28 $(11.7 \%)$ and $1(0.4 \%)$, respectively. Transmission rates of infection in the neonates for $N$. gonorrhoeae and C. trachomatis, born to the infected mothers, were 28/37 (75.6\%) and $1 / 3$, respectively. No case of co-infection with $N$. gonorrhoeae and $C$. trachomatis was detected in the neonates, as was the case with mothers.

\section{Discussion}

$C$. trachomatis and $N$. gonorrhoeae are the most common causes of sexually transmitted infections leading to 
serious conditions in pregnant women and their neonates. Prior to this study, limited data existed on C. trachomatis and $N$. gonorrhoeae prevalence among the Iranian pregnant women with no clinical symptoms and their neonates. Therefore, the present study provides documented data for the first time in Iran on the vertical transmission rates of these two organisms in the neonates. A PCR assay which is more sensitive and specific, compared to other methods such as culture as gold standard, was used $[18,19]$.

The results revealed that 37 (15.5\%) pregnant women were infected with C. trachomatis. Previous studies showed that the frequency of $C$. trachomatis among women varies in different countries, and even within the same country.

Previous studies have reported that the frequency of $C$. trachomatis infection among pregnant women is 2.5 to $4.74 \%$ in the United States [20, 21], 1.9 to $14.9 \%$ in Asia [2], 1.6 to $16.4 \%$ in Europe [2, 22], 5.2 to $18.6 \%$ in Africa [2], and 10.9 to $30.6 \%$ in Oceania [2]. Differences in frequency could be explained by sociodemographic factors; different sensitivities of the diagnostic methods used and specimen types collected. Unlike in some previous studies, no association was found between C.trachomatis prevalence and age and educational status in the pregnant women in the present study [23, 24].

The prevalence of eye colonization with $C$. trachomatis in the neonates was found to be $11.7 \%$ in this study, which varies in different studies, ranging between 1.6 to $18 \%$ [3, 4]. This difference is probably due to the different sensitivity of the methods used in such studies and varying prevalence of infections among mothers throughout the world.

The vertical transmission rate of $C$. trachomatis was $75.6 \%$ which is in agreement with reported rates in other studies $[3,4]$ but in contrast to a study by Jilian et al., which reported a lower rate of vertical transmission [25]. The discrepancy in these two findings may be due to different target populations [25].

Consistent with other studies, $N$. gonorrhoeae had a low prevalence of $1.3 \%$ in the pregnant women [26, 27]. Similar to $C$. trachomatis, there was no significant relationship between the prevalence of $N$. gonorrhoeae and the mothers' educational status and age. The prevalence of eye infection and rate of vertical transmission with $N$. gonorrhoeae in the neonates were $0.4 \%$ and $1 / 3$ respectively, consistent with some other studies $[3,28]$. No concomitant $C$. trachomatis and $N$. gonorrhoeae infection was detected in mothers or neonates while all positive neonates were born to the infected mothers.

Studies show that ocular prophylaxis in neonates was effective against gonoccocal eye infection, whereas it may not be the case for chlamydial conjunctivitis [29, 30]. Neither can it prohibit colonization or infection at other sites like nasopharynx, rectum, and vagina; conversely, it may increase antimicrobial resistance and cause some level of toxicity [31,32]. Overall, ocular prophylaxis may help to prevent chlamydial neonatal conjunctivitis, but not that much to help to prevent gonococcal neonatal conjunctivitis [29].

In Iran, prenatal screening and treatment is not a part of the routine program for mothers care and consequently there is a chance of transmitted C. trachomatis and $N$. gonorrhoeae as a common cause of neonatal conjunctivitis.

\section{Conclusion}

Prenatal screening and treatment of pregnant women have been demonstrated to be very effective for the prevention of neonatal chlamydial and gonococcal infections. Given the above mentioned findings, we can conclude that in the absence of a program for screening and treatment of pregnant women and in areas with a considerable prevalence of such organisms, it is suggested that at least ocular prophylaxis with antibiotics be incorporated in the routine neonatal care program for the prevention of chlamydial and gonococcal ophthalmia.

\section{Abbreviations \\ C. trachomatis: Chlamydia trachomatis; N. gonorrhoeae: Neisseria gonorrhoeae}

\section{Acknowledgements}

We express our deep thanks to $\mathrm{H}$. Khajehei, PhD for linguistic editing of the manuscript.

\section{Funding}

The study was financially supported by Professor Alborzi Clinical Microbiology Research Center of Shiraz University of Medical Sciences. The funders had no role in study design, data collection and the decision to submit the work for publication.

\section{Availability of data and materials}

The datasets used and/or analysed during the current study are available from the corresponding author on reasonable request.

\section{Author's contributions}

$B P$, co-ordination and supervision of $L A B$ work and critical reading of the manuscript. MS, study conception and design. ZR and JM, data analysis and interpretation, $\mathrm{LAB}$ work and manuscript preparation. AA, co-ordination and design of the study and critical reading of the manuscript. All authors read and approved the final manuscript.

\section{Ethics approval and consent to participate}

The study was approved by and carried out under the guidelines of the medical ethics committee at Shiraz University of Medical Sciences, Shiraz, Iran. Written informed consents and filled questionnaires on age and education from the neonates' parents and participating mothers (mean age 27.7; range: $18-45$ years) were obtained for sample collection and subsequent analysis. In doing so, we used written forms filled by the participants themselves (those who were educated) or by the visitors, who accompanied the illiterate ones and on behalf of them. The items in both consent form and questionnaires were initially read for the illiterate participants and filled by the accompanying visitors based on their answers.

Consent for publication

Not applicable.

Competing interests

The authors declare that they have no competing interests. 


\section{Publisher's Note}

Springer Nature remains neutral with regard to jurisdictional claims in published maps and institutional affiliations.

\section{Author details}

'Professor Alborzi Clinical Microbiology Research Center, Shiraz University of Medical Sciences, Shiraz, Iran. ${ }^{2}$ Departments of Microbiology, School of Medicine, Gonabad University of Medical Sciences, Gonabad, Iran.

Received: 20 September 2017 Accepted: 13 September 2018 Published online: 24 September 2018

\section{References}

1. Darville T. Chlamydia trachomatis infections in neonates and young children. Semin Pediatr Infect Dis. 2005:16(4):235-44.

2. Newman L, Rowley J, Vander Hoorn S, et al. Global estimates of the prevalence and incidence of four curable sexually transmitted infections in 2012 based on systematic review and global reporting. PLoS One. 2015; 10(12):e0143304.

3. Justel M, Alexandre I, Martínez $P$, et al. Vertical transmission of bacterial eye infections, Angola, 2011-2012. Emerg Infect Dis. 2015;21(3):471-3.

4. Schachter J, Grossman M, Sweet RL, et al. Prospective study of perinatal transmission of chlamydia trachomatis. JAMA. 1986;255:3374-7.

5. Hammerschlag MR. Chlamydial and gonococcal infections in infants and children. Clin Infect Dis. 2011;53(Suppl 3):S99-102.

6. Ahmadi MH, Mirsalehian A, Bahador A. Prevalence of genital chlamydia trachomatis in Iran: a systematic review and meta-analysis. Pathog Glob Health. 2015;109(6):290-9.

7. Haghighi Hasanabad M, Mohammadzadeh M, Bahador A, Fazel N, Rakhshani H Majnooni A. Prevalence of Chlamydia trachomatis and Mycoplasma genitalium in. pregnant women of Sabzevar-Iran. Iran J Microbiol. 2011;3(3):123-8.

8. Rashidi B, Chamani L, Haghollahi F, et al. Prevalence of Chlamydia trachomatis infection in fertile and infertile women; a molecular and serological study. J Reprod Infertil. 2009;10:32-41.

9. Jahromi AS, Farjam MR, Mogharrab F, Amiryan M, Makiani MJ, Madani A, et al. Chlamydia trachomatis in women with full-term deliveries and women with abortion. Am J Infect Dis. 2010:3:66-9.

10. Janghorban R, Azarkish F. An overview on sexually transmitted infections in Iran. Int J Reprod Contracept Obstet Gynecol. 2016;5(3):585-95.

11. Hassanzadeh P, Mardaneh J, Motamedifar M. Conventional agar-based culture method, and nucleic acid amplification test (NAAT) of the cppB gene for detection of Neisseria gonorrhea in pregnant women Endocervical swab specimens. Iran Red Crescent Med J. 2013;15(3):207-11.

12. Wager GP, Martin DH, Koutsky L, et al. Puerperal infectious morbidity: relationship to route of delivery and to antepartum chlamydia trachomatis infection. Am J Obstet Gynecol. 1980;138:1028-33.

13. Gencay M, Koskiniemi M, Ammaälaä $P$, et al. Chlamydia trachomatis seropositivity is associated both with stillbirth and preterm delivery. APMIS 2000;108:584-8

14. Hammerschlag MR, Chandler JW, Alexander ER, et al. Longitudinal studies of chlamydial infection in the first year of life. Pediatr Infect Dis. 1982;1:395-401.

15. American Academy of Pediatrics. Chlamydial infections. In: Pickering LK, Baker CJ, Long SS, eds. Red Book: 2006 Report of the Committee on Infectious Diseases. 27th ed. Elk Grove Village, III: Am Acad Pediatr. 2006; 249-257.

16. Zuppa AA, D'Andrea V, Catenazzi $P$, et al. Ophthalmia neonatorum: what kind of prophylaxis? J Matern Fetal Neonatal Med. 2011;24(6):769-73.

17. Bell TA, Stamm WE, Kuo CC, et al. Risk of perinatal transmission of chlamydia trachomatis by mode of delivery. J Inf Secur. 1994;29(2):165-9.

18. Watson EJ, Templeton A, Russell I, et al. The accuracy and efficacy of screening tests for chlamydia trachomatis: a systematic review. J Med Microbiol. 2002;51(12):1021-31

19. Centers for Disease Control and Prevention. Recommendations for the laboratory-based detection of Chlamydia trachomatis and Neisseria gonorrhoeae--2014. MMWR Recomm Rep. 2014;63(RR-02):1-19.

20. Datta SD, Sternberg M, Johnson RE, et al. Gonorrhea and chlamydia in the United States among persons 14 to 39 years of age, 1999 to 2002. Ann Intern Med. 2007;147(2):89-96.

21. Miller WC, Ford CA, Morris M, Handcock MS, et al. Prevalence of chlamydial and gonococcal infections among young adults in the United States. JAMA. 2004;291(18):2229-36.
22. Goulet V, de Barbeyrac B, Raherison S, et al. Prevalence of chlamydia trachomatis: results from the first national population-based survey in France. Sex Transm Infect. 2010;86(4):263-70.

23. Romoren M, Sundby J, Velauthapillai M, et al. Chlamydia and gonorrhoea in pregnant Batswana women: time to discard the syndromic approach? BMC Infect Dis. 2007;7:27.

24. Harrison HR, Alexander ER, Weinstein L, et al. Cervical chlamydia trachomatis and mycoplasmal infections in pregnancy. Epidemiology and outcomes. JAMA. 1983;250(13):1721-7.

25. $\mathrm{Yu} J, \mathrm{Wu} \mathrm{H}$, Li F, et al. Vertical transmission of chlamydia trachomatis in Chongqingn China. Curr Microbiol. 2009:58:315-20.

26. Borges-Costa J, Matos C, Pereira F. Sexually transmitted infections in pregnant adolescents: prevalence and association with maternal and foetal morbidity. J Eur Acad Dermatol Venereol. 2012;26(8):972-5.

27. Panaretto KS, Lee HM, Mitchell MR, et al. Prevalence of sexually transmitted infections in pregnant urban aboriginal and Torres Strait islander women in northern Australia. Aust N Z J Obstet Gynaecol. 2006;46(3):217-24.

28. Laga M, Plummer FA, Nzanze H, et al. Epidemiology of ophthalmia neonatorum in Kenya. Lancet. 1986;2(8516):1145-9.

29. Darling EK, McDonald H. A meta-analysis of the efficacy of ocular prophylactic agents used for the prevention of gonococcal and chlamydial ophthalmia neonatorum. J Midwifery Womens Health. 2010;55(4):319-27.

30. Ramirez-Ortiz MA, Rodriguez-Almaraz M, Ochoa-Diazlopez $\mathrm{H}$, et al Randomised equivalency trial comparing 2.5\% povidone-iodine drops and ophthalmic chloramphenicol for preventing neonatal conjunctivitis in a trachoma endemic area in southern Mexico. Br J Ophthalmol. 2007:91(11): $1430-4$.

31. Hammerschlag MR, Chandler JW, Alexander ER, et al. Erythromycin ointment for ocular prophylaxis of neonatal chlamydial infection. JAMA 1980;244(20):2291-3.

32. Public Health Agency of Canada, National Microbiology Laboratory. National surveillance of antimicrobial susceptibilities of Neisseria gonorrhoeae. Annual Summary 2012: http://publications. gc.ca/collections/collection 2014/aspc-phac/HP57-3-2012-eng.pdf

\section{Ready to submit your research? Choose BMC and benefit from:}

- fast, convenient online submission

- thorough peer review by experienced researchers in your field

- rapid publication on acceptance

- support for research data, including large and complex data types

- gold Open Access which fosters wider collaboration and increased citations

- maximum visibility for your research: over $100 \mathrm{M}$ website views per year

At BMC, research is always in progress.

Learn more biomedcentral.com/submissions 